\title{
REBEn $\begin{aligned} & \text { Transformações na administração em } \\ & \text { enfermagem no suporte aos transplantes no Brasil }\end{aligned}$
}

\author{
Changes in nursing administration in supporting transplantation in Brazil \\ Cambios en la administración de enfermería en apoyo de los transplantes en Brasil
}

\section{Vivian Cintra \\ Acadêmica do $4^{\circ}$ ano da Faculdade de Enfermagem da Universidade de Santo Amaro, \\ São Paulo enfvivian@hotmail.com \\ Maria Cristina Sanna}

Enfermeira, Doutora em Enfermagem. Professora Titular da Faculdade de Enfermagem da Universidade de Santo Amaro. Líder do Centro de Estudos e Pesquisas sobre a História da Enfermagem da UNISA

Trabalho de Conclusão de Curso de Graduação em Enfermagem da Faculdade de Enfermagem da Universidade de Santo Amaro - viinculado à Linha de Pesquisa História da Administração de Enfermagem.

\section{RESUMO}

Estudo bibliográfico, de caráter histórico, cujo objetivo foi compreender como a Enfermagem se estruturou para gerenciar a assistência nos transplantes. O rastreamento de publicações foi feito nas bases de dados HISA, LILACS, BDENF, PERIENF e DEDALUS, e usou como recorte temporal o primeiro transplante renal, realizado em 1965 até a publicação do último artigo científico do ano de 2003. Das treze publicações encontradas, dez eram artigos científicos, duas dissertações de mestrado e uma tese de doutorado. Após a leitura dos textos foi feito 0 agrupamento por similaridade e pertinência, construindo-se 0 eixo temático para a apresentação dos resultados. Estes indicaram ativa participação da Enfermagem frente às similaridades e aos diferentes tipos de transplantes realizados nesses quase 40 anos de história.

Descritores: Transplante; Cuidados de enfermagem; História da enfermagem; Brasil.

\section{ABSTRACT}

This historical and bibliographic study aimed to understand how Nursing was organized to support care in transplantation. The HISA, LILACS, BDENF, PERIENF and DEDALUS databases were consulted, and thirteen references were found, ten of which were scientific articles, two were master's dissertations and one was a doctoral thesis. The span of time chosen for study ranges from the date of the first kidney transplant in Brazil (1965), to the date of publication of the last scientific article found in the databases mentioned above (2003). After reading these articles, the ones that were similar in topic were grouped together, thus creating the thematic axis for the presentation of the results. The results showed that the Nursing profession has played an important and active role in transplants ever since the first procedure in 1965.

Descriptors: Transplantation; Nursing care; History of nursing; Brazil.

\section{RESUMEN}

Estudio bibliográfico, de carácter histórico, cuyo objetivo fue comprender cómo la Enfermería se organizó para brindar un apoyo a los transplantes. Se buscaron publicaciones en las bases de datos HISA, LILACS, BDENF, PERIENF Y DEDALUS, y se tomó como referencia temporal el período comprendido entre el primer transplante renal, realizado en 1965, y la publicación del último artículo científico del año 2003. De las trece publicaciones diez eran artículos científicos, dos disertaciones de maestría y una tesis de doctorado. Después de la lectura de los textos, éstos fueron agrupados por similitud y pertinencia, lo que sirvió para elaborar el eje temático para la presentación de los resultados. Éstos revelaron que la Enfermería participó activamente en los diferentes tipos de transplantes realizados en esos casi 40 años de historia.

Descriptores: Transplantes; Atención de enfermería; Historia de la enfermería; Brasil.

Cintra V, Sanna MC. Transformações na administração em enfermagem no suporte aos transplantes no Brasil. Rev Bras Enferm 2005 jan-fev; 58(1):78-81.

\section{INTRODUÇÃO}

Transplante é a remoção ou isolamento parcial de uma parte do corpo e seu implante no corpo da mesma pessoa ou de outra ${ }^{(1)}$. É um procedimento terapêutico bem estabelecido e que apresenta progressos quanto a seus resultados, em decorrência do aprimoramento da técnica cirúrgica, de novos medicamentos imunossupressores, de métodos mais eficazes de conservação de órgãos e da melhor compreensão e controle de fenômenos imunológicos ${ }^{(2)}$.

O transplante de órgãos e tecidos requer uma infra-estrutura de apoio bastante complexa, 0 que o torna um recurso muito dispendioso e de alcance muito restrito, embora em expansão nos países em desenvolvimento ${ }^{(2)}$.

A Enfermagem, que incorpora o saber de várias ciências em sua formação profissional, dentre elas, a Administração(3) , se fez presente desde os primórdios da realização do primeiro transplante no Brasil, em 1965, o transplante renal(4).

Esta ciência contribui com uma parcela que se concretiza, principalmente, na administração de pessoal(3) e no desfeche da subordinação da administração aos fins da Enfermagem ${ }^{(5)}$.

Administração é um processo de tomar decisões e realizar ações que compreende quatro 
processos principais interligados: planejamento, organização, execução e controle. É o processo de realizar e alcançar ações que utilizam recursos. A principal razão para o estudo da administração é o seu impacto sobre o desempenho das organizações. É a forma como são administradas que torna as organizações mais ou menos capazes de utilizar corretamente seus recursos para atingir os seus objetivos ${ }^{(6)}$. Seu ensino na Enfermagem brasileira é documentado desde a década de 40 do século $X X^{(7)}$, 0 que significa que está a serviço da Enfermagem há mais tempo que o da introdução dos transplantes no país.

Os programas de transplantes de órgãos tiveram início no final da década de 1940, em Paris, Londres, Edimburgo e Boston. O primeiro transplante renal documentado ocorreu em 1933 pelo Dr. Voronoy. No entanto, só em 1954, foi realizado o primeiro transplante renal com sucesso, por Joseph Murray, na cidade de Boston, com gêmeos idênticos. Em 1962, houve o primeiro transplante bem sucedido feito com um doador cadáver. Isto só foi possível devido ao desenvolvimento de novas drogas imunossupressoras ${ }^{(8)}$.

A equipe do Dr. Hardy e colaboradores, dos Estados Unidos, realizou o primeiro transplante de pulmão em 1963. Não tiveram muito êxito devido à morte do paciente. No mesmo ano ocorreu o primeiro transplante hepático experimental, realizado por Thomas Starzl, na Universidade de Colorado - EUA ${ }^{(8)}$.

Após ingentes esforços e inúmeras experiências em animais de laboratório, foi realizado, no Brasil, pela equipe médica do Hospital das Clínicas da Faculdade de Medicina de São Paulo em janeiro de 1965, 0 primeiro transplante renal em ser humano ${ }^{(4)}$.

Todavia, em maio de 1968, o transplante que teve maior repercussão desta nova era da prática terapêutica, foi o transplante cardíaco, passando a ser considerado o primeiro transplante realizado no Brasil e $017^{\circ}$. no mundo, praticado no Hospital das Clínicas da Universidade de São Paulo, pela equipe liderada pelo Prof. Euryclides de Jesus Zerbini. Todo o processo para o procedimento foi elaborado em conjunto pelas equipes médica e de enfermagem: como os profissionais seriam divididos, as salas cirúrgicas, todo o intra-operatório e o pós-operatório, as técnicas mais adequadas e 0 isolamento do paciente ${ }^{(9)}$.

Na década de 70 do século XX, houve um grande avanço nos transplante de órgãos em todo o mundo, devido ao desenvolvimento da ciclosporina, em 1972. Esta droga imunossupressora permitiu aumentar a expectativa e qualidade de vida dos receptores ${ }^{(8)}$.

Em 1981, um grupo de americanos da Universidade de Stanford (Califórnia - EUA), realizou com sucesso o primeiro transplante combinado "coração-pulmões". Já no ano de 1983, o primeiro transplante hepático deixou de ser experimental, sendo considerado como modalidade terapêutica para doenças hepáticas terminais ${ }^{(8)}$.

Para que esses sucessos fossem obtidos, a participação da enfermeira em desenvolver atividades específicas nessa modalidade foi vital neste tipo de serviço, atuando de formas distintas em locais como: Centro de Captação de Órgãos, Unidade de Terapia Intensiva, Centro Cirúrgico, Unidade de Internação e Ambulatório ${ }^{(10)}$.

A Enfermagem precisa ser capaz de suprir as necessidades básicas de um transplante, considerando o grau de complexidade que este envolve, precisando ser muito bem treinada, capacitada e atualizada, acompanhando a evolução tecnológica e científica.

A atuação da enfermeira ao gerenciar o serviço de transplante é de extrema valia, haja vista a importância do serviço prestado e a complexidade terapêutica envolvida, contribuindo não só para o alcance das metas assistenciais pretendidas como para o reconhecimento social desta classe profissional.

A inexistência de estudos que abordem este tema e a importância de se sistematizar o conhecimento existente a respeito, revelará, à Enfermagem, os métodos empregados para gerenciar os recursos necessários à realização dos transplantes, contribuindo na compreensão dessa trajetória e sua implicação na implantação de serviços semelhantes e desenvolvimento dos já existentes.

A Enfermagem, como categoria profissional, possui meios que possibilitem a congruência da ação organizacional, através dos recursos administrativos e, usufruindo de seus conhecimentos, habilidades e atitudes em gerenciamento é capaz de prover 0 ambiente adequado à realização de quaisquer tipos de transplante.

A experiência da autora principal do presente estudo na atuação em procedimentos cirúrgicos, junto à equipe pioneiramente reconhecida para realizar transplante de pâncreas, no Hospital Beneficência Portuguesa de São Paulo, também levou ao interesse de investigar como a Enfermagem atuou frente à complexidade deste tipo de procedimento existente nos grandes centros transplantadores, no decorrer dos tempos.

Assim, o presente trabalho tem por objetivo identificar, no período de 1965 a 2003, como a Enfermagem se estruturou para gerenciar a assistência de enfermagem frente à situação dos transplantes, na visão das enfermeiras que escreveram sobre este tema.

\section{METODOLOGIA}

Com o intuito de encontrar na literatura científica nacional, publicação sobre o gerenciamento da assistência de enfermagem nos transplantes, procurou-se realizar um levantamento bibliográfico, a fim de procurar, neste material, as propostas de cada autor para o tema em análise.

O recorte temporal iniciou-se com o surgimento do relato do primeiro transplante realizado no Brasil no ano de 1965, até a publicação do último artigo científico no ano de 2003 sobre o tema, período estabelecido considerando 0 ano da primeira e da última publicação encontradas sobre o referido tema vinculadas ao surgimento do primeiro procedimento realizado no Brasil até o último marco histórico relatado.

A população do estudo foi constituída de publicações científicas rastreadas na Seção de Automação do Serviço de Biblioteca, pelo sistema Integrado da Escola de Enfermagem da Universidade de São Paulo. As palavras-chaves utilizadas - "enfermagem, transplante, unidade de transplante", foram buscadas nas bases de dados eletrônicas: HISA - que reúne a literatura sobre a História da Saúde Pública na América Latina e Caribe, LILACS - que reúne a Literatura Latino América e do Caribe em Ciências da Saúde; BDEnf - que reúne a Literatura Brasileira em Enfermagem; o Dedalus - que reúne a literatura publicada na forma de livros, teses e eventos registrados no Banco de Dados Bibliográficos da Universidade de São Paulo; e o PERIEnf - que reúne a literatura publicada em periódicos brasileiros por enfermeiras, na forma de artigos pertencentes ao Banco de Dados Bibliográficos da Escola de Enfermagem da Universidade de São Paulo.

Dessa busca resultou o encontro de dezesseis publicações, sendo treze artigos científicos, duas dissertações de mestrado e uma tese de doutorado abordando o tema proposto. Dessas foram excluídos três artigos científicos por não estarem relacionados ao objeto de estudo, tratando de Doação de órgãos, Central de Transplantes de Órgãos e Legislação na Captação de Órgãos.

Após o levantamento das citações ocorreu a leitura dos artigos e teses, e posterior fichamento, cuja compilação enfocou o objeto do estudo proposto. Os dados foram agrupados por similaridade e pertinência e, a partir daí, se deu a construção do eixo temático para a apresentação dos resultados.

\section{RESULTADOS E DISCUSSÃO}

Os achados foram ordenados segundo o eixo temático construído, que reuniu a base da redação deste relatório de pesquisa, no qual foram apostas as informações encontradas, suas fontes e as reflexões da pesquisadora sobre elas, dividindo em quatro categorias: "Preocupandose com a Infecção", "Olhando para o Cliente e Trabalhando em Equipe", "Normatizando os Serviços de Transplante" e Ampliando a Atuação e Pensando na Especialização".

\subsection{Preocupando-se com a Infecção}

A década de 60 do século XX foi marcada pelo início dos transplantes no Brasil, figurando a participação da Enfermagem no período transoperatório, tendo o recurso físico e material como foco. O preparo da sala de cirurgia enfatizava a planta física desta e do centro cirúrgico como um todo, e os materiais e equipamentos do quarto do paciente no pós-operatório imediato ${ }^{(4,11)}$. 
O recurso material enfocava a esterilização de instrumentais, roupas da equipe de trabalho e do paciente e objetos pessoais do paciente, a fim de combater qualquer meio de infecção com eficácia, fazendo com que o risco de perda do paciente transplantado - receptor, se restringisse à rejeição do órgão, pois ainda não havia medicações imunossupressoras eficientes, o que representava alto índice de insucesso da terapêutica ${ }^{(4)}$.

Frente a esse desafio, a Enfermagem também começou a perceber a necessidade de interagir com outros departamentos do hospital ${ }^{(4,11)}$.

A preocupação com os recursos humanos se dava pela escassez de enfermeiros no mercado de trabalho, havendo a necessidade de contratar mais auxiliares de enfermagem para dar apoio aos enfermeiros, principalmente no período pós-operatório, como explicou Bernardes ${ }^{(4)}$.

O primeiro cuidado que devemos observar na escolha do pessoal é afastar os portadores de qualquer tipo de moléstias... deve-se escalar pessoal habilitado e com boa formação profissional e, na impossibilidade de se contar com enfermeiros nas 24 horas, poderemos utilizar auxiliares de enfermagem previamente treinados para esse mister, além da pessoa escalada para ministrar os cuidados diretos ao receptor, deveremos manter um circulante externo que poderá ser um atendente devidamente orientado.

A atenção para o risco de infecção era enorme, fazendo com que todos selecionados para atuar junto à equipe de enfermagem fossem submetidos a exames laboratoriais, como pré-requisito admissional, sendo os considerados "doentes", desclassificados(4).

Os enfermeiros e auxiliares de enfermagem deveriam ser qualificados, sendo submetidos a treinamentos específicos constando da unidade de transplante, enfermeiros nas 24 horas de todos os dias, os quais exerciam a função exclusivamente assistencial ao paciente e também apoio ao familiar(4).

\subsection{Olhando para o Cliente e Trabalhando em Equipe}

Nos anos 70 do século XX, a Enfermagem começou a expandir seu papel gerencial no período intra-operatório e no pós-operatório, tanto do doador como do receptor, com a atenção mais voltada ao primeiro. Até então não se relatava tanto os aspectos emocionais ligados ao doente, valorizando apenas os procedimentos técnicos.

A partir de então, a atuação da enfermeira estendeu-se do momento da internação ao pós-operatório mediato. Mesmo ainda estando concentrada no ato operatório em si, já havia evidências de preocupação com o paciente, antes e fora do ato cirúrgico, sob a coordenação da enfermeira que, antes, se preocupava mais com os recursos físicos, materiais e humanos, deixando de lado o paciente ${ }^{(12)}$.

Nessa época também se inicia a integração de outros setores, como a Farmácia interagindo com a Enfermagem. Surge ainda a idéia dos grupos permanentes, estabelecendo-se comissões, como notificado por Couto, Fukumara ${ }^{(13)}$ em relação à Comissão de Transplante do Hospital dos Servidores Públicos do Estado de São Paulo.

Como conseqüência, criou-se a padronização das condutas do serviço o que cabia ao enfermeiro, melhorando a sua atuação e reorientado o trabalho para o gerenciamento da assistência de enfermagem.

A principal função da enfermeira era de coordenação e supervisão das salas de cirurgia que atendiam simultaneamente receptor e doador:

Para o sucesso da cirurgia o grupo médico e de enfermagem deverão ter uma só filosofia, trabalhando em equipe e em coordenação perfeita. Partindo daí todas as cirurgias deverão ser planejadas empregando todos os processos de assepsia. A enfermeira tem um papel de destaque juntamente com o anestesista, planeja e organiza todo o material necessário(12).

Os artigos ${ }^{(12,13)}$ revelam que a Enfermagem era extremamente prescritiva, descrevendo em detalhes como deveriam ser as ações do ato operatório, anestésico e cirúrgico, e relatando as principais ações na forma como aconteciam, transcrevendo nos prontuários dos pacientes todos os acontecimentos, oferecendo aos demais profissionais o produto do seu trabalho.

\subsection{Normatizando os Serviços de Transplante}

A década de 80 do século XX foi marcada pela formação de alguns centros transplantadores, como o CEMO - Centro Nacional de Medula Óssea, como referencia nacional no Estado do Rio de Janeiro junto ao Inca- Instituto Nacional de Câncer, fundado em 1982, desafiando 0 Serviço de Enfermagem do Instituto que pouco conhecia sobre a técnica de transplante de medula óssea ${ }^{(14)}$.

A Enfermagem conseguiu desvendar alguns mistérios da pratica terapêutica dos transplantes com as experiências diárias das enfermeiras que trabalhavam nos grandes centros transplantadores, enfatizando 0 treinamento das enfermeiras como base para melhora da qualidade da assistência $^{(14)}$

Nesse momento, a participação do enfermeiro em intercâmbios nacionais e internacionais acabou por embasar, orientar e facilitar as decisões de mudanças, resultando no início da construção de protocolos e normatizações de procedimentos, com a criação de Manuais e outros instrumentos de informação(15).

Nota-se a escassez de publicações de artigos científicos, indagandose o porquê se deixou de publicar nessa década. As modificações neste período não foram relevantes? Os aspectos gerenciais não eram preponderantes? O que se pode afirmar é que, embora este período tenha ficado marcado pela escassez de pesquisas científicas sobre 0 tema, observou-se, em uma dissertação de mestrado ${ }^{15}$, que os enfermeiros assistenciais que contribuíram para a implantação de serviços de transplantes, embora atentos à assistência ao paciente, não descuidaram dos aspectos gerenciais, ressaltando ações como a previsão e aplicação de recursos humanos, materiais e técnicos no transoperatório, condizentes com as ações de planejamento, organização e implementação da assistência de enfermagem.

A Enfermagem começou a preocupar-se em interagir mais com a família, observando sua influência na melhora e do paciente ainda na década de $80^{(15)}$, mas foi nos anos 90 do século XX que essa preocupação se acentuou.

\subsection{Ampliando a Atuação e Pensando na Especialização}

Essa década foi marcada pela expansão do papel gerencial da enfermeira, não mais restrita ao ato operatório, indo do processo da admissão de pacientes nos programas de transplantes elaborados por enfermeiras ${ }^{(16)}$, passando pelo processo de captação de órgãos, pela assistência e gerência na unidade de internação, no trans-operatório ${ }^{(17)}$ e pós-alta hospitalar(18), estendendo, à Enfermagem, 0 acesso a todo 0 procedimento terapêutico, identificando-se, na enfermeira, principalmente, a função de coordenadora, cuja presença era de extrema importância para o total sucesso do transplante.

Em 1990, ocorreu a implantação do Serviço de Transplante de Medula Óssea no Hospital das Clínicas da Faculdade de Medicina de Ribeirão Preto da Universidade de São Paulo(18) (HCFMRP-SP).

No ano 2000, com a multiplicação dos centros transplantadores, ficou explícito o papel do enfermeiro nesta prática, reassegurando a importância de sua figura para gerenciar estes institutos complexos, pela sua capacidade de suprir as necessidades dos variados tipos de transplantes. Nessa época o enfermeiro, passa inclusive, a ser protagonista na atividade no centro cirúrgico, na captação e implantação de enxerto ósseo.

O Hospital das Clínicas da Faculdade de Medicina da Universidade de São Paulo, que dispõe do serviço de Banco de Tecidos no Instituto de Ortopedia e Traumatologia, responsável por captar, armazenar e viabilizar os transplantes de tecidos do sistema músculo-esquelético retirados de pessoas com morte cerebral, sempre após a autorização da família, desde 1995, fez uma reestruturação em que ocorreu a integração da Enfermagem com a equipe médica em todo o processo, desde a captação ao transplante, sendo um centro pioneiro na união da Enfermagem com a equipe médica ${ }^{(19)}$.

Reconhece-se, portanto, na enfermeira, uma referência em treinar e orientar os novos enfermeiros ingressantes nos serviços de transplantes mas, ao contrário do que seria esperado, a Enfermagem 
nos transplantes não evoluiu ainda para uma especialização( ${ }^{(17)}$, com formação específica, teórica e prática, para a atuação nesse campo. Apenas em 2003 foi possível encontrar uma referência ${ }^{(20)}$ sobre a formação de enfermeira especialista em transplante, formada pela Escola de Enfermagem da Universidade Federal de Minas Gerais.

\section{CONCLUSÕES}

Do estudo realizado pode-se concluir que a Enfermagem transformou o seu papel gerencial utilizando os recursos humanos, materiais e físicos inicialmente focados no período intra-operatório, evoluindo, no decorrer dos tempos, para o exercício da função da enfermagem muito além dos limites cirúrgicos, tornando-se gradativamente autônoma e protagonista real de uma futura especialidade desta área.

Atualmente, o Brasil possui o maior programa público de transplantes de órgãos e tecidos do mundo, e é o segundo país no mundo em número de transplantes, só perdendo para os Estados Unidos ${ }^{(21)}$.

Segundo a estimativa do Ministério da Saúde ${ }^{(21)}$, em 2003 realizouse 8,1 mil transplantes e havia mais de 56 mil pessoas precisando de doações, pretendendo-se diminuir a fila dos transplantes atuais para 22 mil nos próximos quatro anos. Em 2002, a córnea encabeçou a lista dos órgãos e tecidos mais transplantados, com 3.496 procedimentos.
Em seguida o rim (2.645), a medula óssea (871), o fígado (523), a esclera (132), o coração (126), o rim/pâncreas (100), o pulmão (21), o pâncreas (17), e o pâncreas após rim (12).

Alguns médicos buscaram, nos grandes centros transplantadores, conhecimento acerca da terapêutica, infra-estrutura e organização para a implantação deste tipo de serviço em outros centros ${ }^{(10)}$.

Hoje, há uma grande rede de hospitais capacitados para realização de transplantes, prontos a executar um número bem maior dessas operações, difundindo e desenvolvendo estas técnicas nos grandes centros hospitalares, onde há recursos materiais, físicos e humanos capazes de suprir a necessidade desta terapêutica. Até o Conselho federal de Enfermagem, em sua Resolução 292/2004 normatizou a atuação do enfermeiro nos transplantes, incumbindo-lhe explicitamente de "planejar, executar, coordenar, supervisionar e avaliar os procedimentos de enfermagem"(22).

Nada disto, porém, como comprovam os resultados do presente trabalho, poderia ter sido alcançado sem a ativa participação da Enfermagem frente às singularidades e peculiaridades dos diferentes tipos de transplantes realizados no decorrer dos quase 40 anos da história que aqui se termina de relatar.

\section{REFERÊNCIAS}

1. Sabinston DC. Tratado de cirurgia. As bases biológicas da prática cirúrgica moderna. Rio de Janeiro (RJ): Guanabara-Koogan; 1993.

2. Petroiannu A. Lições de cirurgia. Rio de Janeiro (RJ): Interlivros; 1997.

3. KurcgantP. Administração em Enfermagem. São Paulo (SP): EPU; 1991.

4. Bernardes GJ, Constantino N, Camargo LT, Osoegawa S. Enfermagem em transplante renal. Rev Bras Enferm 1996;49(5/6): 595-605.

5. Trevizan MA. Enfermagem hospitalar: administração e burocracia. Brasília (DF): Editora da Universidade de Brasília; 1983.

6. Maximiano ACA. Introdução à administração. 5ª ed. São Paulo (SP): Atlas; 2000.

7. Sanna MC. $O$ ensino da arte de administrar em enfermagem na Escola de Enfermagem Anna Nery no início dos anos 40: um estudo de caso. [tese pós-doutorado] Rio de Janeiro (RJ): Escola de Enfermagem Anna Nery, Universidade Federal do Rio de Janeiro; 2001.

8. Cintra EA, Nishide VM, Nunes WA. Assistência de enfermagem ao paciente crítico. São Paulo (SP): Atheneu; 2000.

9. Sanna MC. Histórias de enfermeiras gerentes: subsídios para a compreensão de um modelo referência de organização de serviços de enfermagem no período de 1950 a 1980. Rio de Janeiro (RJ): Editora Anna Nery; 2002.

10. Sasso KD, Azevedo MAJ. Assistência de enfermagem no transplante de fígado: a importância do enfermeiro nessa modalidade terapêutica. Nursing 2003;60(6):16-20.

11. Ferrarini CDT, Miller MLG, Mello MZR. Transplante de coração enfermagem. Rev Bras Enferm 1968;21(6):529-37.

12. Nozima T. Aspectos de enfermagem relacionados ao Centro Cirúrgico no transplante renal. Rev Paul Hosp 1976;24(12): 565-70.

13. Couto MNV, Fukumara NY. Participação da equipe de enfermagem no transplante renal e no transoperatório. Enfoque 1977; 6(2):8-9.
14. Barreto EMT, Lourenço LHSC, Almeida Filho AJ. O Centro Nacional de Transplante de Medula Óssea no Instituto Nacional de Câncer: os primeiros desafios da implantação. Rev Enf Esc Anna Nery 2003;7(3):406-12.

15. Ishii S. Experiência da equipe de enfermagem num Programa de Transplante Cardíaco [dissertação]. São Paulo (SP): Escola de Enfermagem da Universidade de São Paulo; 1986.

16. Ribeiro CMP, Yamamoto T, Glashan RQ. Proposta de atuação do enfermeiro no programa de transplante pulmonar. Nursing 1998;1(6):14-20.

17. Massarolo MCKB. O Vivencial dos enfermeiros no Programa de Transplante de Fígado de um hospital público cardíaco [tese]. São Paulo (SP): Escola de Enfermagem, Universidade de São Paulo; 1996.

18. Riul S. Contribuição à organização de serviços de transplante de medula óssea e a atuação do enfermeiro [dissertação]. Ribeirão Preto (SP): Escola de Enfermagem de Ribeirão Preto, Universidade de São Paulo; 1995.

19. Soares PMPC, Matos SS. Unidade de Transplante: relato de experiência sobre as ações da enfermeira no cuidado do paciente em pré-operatório de transplante de pâncreas. REME 2003;7(1):52-5.

20. Giovanni A. Encarando Novos Desafios: enfermeiros se destacam no banco de Tecidos do HC. Rev COREN-SP 2003;48:9-12.

21. Doe vida: seja um doador de órgãos. [on-line] Apresenta notícias de realizações do Ministério da Saúde. Brasília (DF); 2003. [citado 26 jun 2004]. Disponível em: URL: http://www.portalweb01.saude.gov.br/ saude/aplicacoes/noticias/noticias_detalhe.cfm?co_seq_noticia $=7534 . \mathrm{html}$.

22. Conselho Federal de Enfermagem. Resolução COFEN No. 292 de 7 de junho de 2004. Normatiza a Atuação do Enfermeiro na Captação e Transplante de Órgãos e Tecidos. Rev COREN-SP 2004;52:18-9. 